\title{
Immunoproteomic analysis of Plasmodium falciparum antigens using sera from patients with clinical history of imported malaria
}

\author{
Rita M Costa ${ }^{1}$, Fátima Nogueira', Karina P de Sousa ${ }^{1}$, Rui Vitorino ${ }^{2}$ and Marcelo S Silva ${ }^{1 *}$
}

\begin{abstract}
Background: The malaria caused by Plasmodium falciparum remains a serious public health problem in the world, due largely to the absence of an effective vaccine. There is a lack of information on the structural properties and antigens capable of activating the immunological mechanisms for the induction of protective immunity. Therefore, the objective of this study is to evaluate the serological reactivity of sera from individuals with imported malaria and identify major immunogenic proteins.
\end{abstract}

Methods: The study was conducted in 227 individuals with imported malaria and 23 healthy individuals who had never been in areas endemic for malaria. The determination of anti- $P$. falciparum IgG antibodies was performed by an ELISA validated and optimized for this study. Sera showing higher reactivity to anti-P. falciparum by ELISA were analysed by immunoblotting and immunogenic proteins were identified by mass spectroscopy.

Results: The results of anti-P. falciparum antibodies research by ELISA indicates 78 positive, 137 negative and 12 indeterminate sera. Analysis of immunoblotting demonstrated a consistent pattern with respect to immunoreactivity of antigens with molecular weights in the range of 40 to $60 \mathrm{kDa}$. Between 40 and $60 \mathrm{kDa}$ six immunogenic proteins were identified: elongation factor-1 alpha (EF-1a), protein disulphide isomerase (PDI); phosphoglycerate kinase (PGK); 78 kDa glucose-regulated protein homologue (GRP-78); rhoptry-associated protein 2 (RAP-2) and rhoptry-associated protein 3 (RAP-3).

Conclusions: It was identified immunogenic proteins essential for parasite survival in the host, two of which (RAP-2 and RAP-3) are already described in the literature as proteins that play an important role in the invasion of erythrocytes by extracellular merozoites.

Keywords: Plasmodium falciparum, Imported malaria, Antibody response, Malaria antigens

\section{Background}

Malaria is an infectious disease caused by unicellular, obligate, intracellular, protozoan parasites belonging to the genus Plasmodium and the main form of transmission is through the bite of the female Anopheles mosquito. There are over 200 species in the genus Plasmodium, but only five species of malaria parasites infect humans: Plasmodium falciparum, Plasmodium ovale, Plasmodium malariae, Plasmodium vivax and Plasmodium knowlesi. Plasmodium falciparum is the most

\footnotetext{
* Correspondence: mssilva@ihmt.unl.pt

${ }^{1}$ Centre for Malaria and Tropical Diseases, Instituto de Higiene e Medicina Tropical, Universidade Nova de Lisboa, Rua da Junqueira, 100, Lisbon 1349-008, Portugal

Full list of author information is available at the end of the article
}

virulent of the human malaria parasites: it can cause severe malaria, a complication that is often fatal and is responsible for the bulk of the malaria-related mortality, particularly in African infants [1].

Malaria is currently endemic in the tropical zones with extensions into the subtropical regions of Asia, Africa, South and Central America. According to the 2011 World Malaria Report, there were an estimated 216 million episodes of malaria and 655,000 worldwide malaria deaths in 2010, 91\% of which were in Africa [2]. Approximately $86 \%$ of malaria deaths globally were children less than five years of age from sub-Saharan Africa [2].

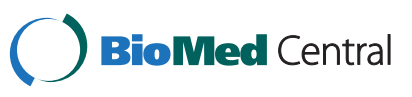

(c) 2013 Costa et al.; licensee BioMed Central Ltd. This is an Open Access article distributed under the terms of the Creative Commons Attribution License (http://creativecommons.org/licenses/by/2.0), which permits unrestricted use, distribution, and reproduction in any medium, provided the original work is properly cited. 
Malaria remains one of the most serious public health problems not only in endemic countries but also in nonendemic areas where the increasing number of imported malaria cases is worrying [3]. In developed countries, imported malaria predominates in tourists and immigrants. Every year, approximately 125 million international travellers visit malaria-endemic areas and 30,000 of them contract the disease [4,5]. Portugal maintains a close relationship with its former colonies for several reasons and so malaria must be suspected in travellers that return from those countries. Malaria is a notifiable disease in Portugal and about 50 cases are reported annually to the National Public Health System [4,6]. Non-immune people (from non-endemic countries) who stay for some time in malaria-affected areas are at increased risk of having severe forms of the disease and can develop symptoms of P. falciparum malaria within a month after leaving the endemic area [7]. In nonendemic countries for malaria, the diagnosis and adequate treatment is delayed due to the fact that malaria is infrequent in these countries, which can make these cases fatal to patients.

The life cycle of malaria parasites is complex. The invasion of erythrocytes by Plasmodium merozoites is a multistep process of specific protein interactions between the parasite and the red blood cell. The first step is the initial recognition and reversible merozoite attachment to the erythrocyte followed by its apical reorientation, irreversible junction formation between the apical end of the merozoites and finally entry into the red cell in a parasitophorous vacuole. This stage of the life cycle is regarded as an attractive target for the development of interventions to combat malaria since the invasion of erythrocytes by the merozoites requires specialized protein expression, such as merozoite surface protein 1 (MSP-1) and a series of highly specific molecular interactions.

The emergence of resistant strains of the parasite, the spread of mosquito strains resistant to insecticides and lack of effective vaccines against malaria are the main factors hampering the fight against the disease. Given the limited exposure of these proteins to the immune system of the host, the antibodies are likely to be the main form of immunity against merozoites [8]. Epidemiological and experimental evidence has revealed the crucial importance of antibody-mediated effector mechanisms directed predominantly at antigens of blood stage parasites [9]. In a similar study, gamma globulin of adults in West Africa was administered to individuals of East Africa with serious infections by $P$. falciparum, which led to the abrupt reduction of parasite density and recovery of clinical disease [10]. In Thai patients, the protective effect of IgG antibodies against African P. falciparum was also demonstrated by passive transfer [11], and antibodies to immune African individuals are capable of controlling the erythrocytic stage of the parasite in Saimiri monkeys [12]. To date, the exact mechanism of protection, whereby the malaria-specific antibodies interfere with the development and/or proliferation of asexual stages of $P$. falciparum, is still not accurately known, and the antigens targeted by protective antibodies remain a topic for discussion.

Immunization with antigens of the erythrocytic phase, particularly antigens from merozoites, has been shown to be protective in various animal models and to have some protective effect in humans [13]. Studies in human and in animal models have shown that the immune response directed to erythrocytic stage antigens may be protective and facilitate the control of infection [14]. It is known that in endemic areas naturally IgG antibodies mediate acquired immunity against $P$. falciparum.

Despite the global importance of $P$. falciparum, most of their proteins have not been yet characterized experimentally. Therefore, the main objective of this study is to evaluate the serological reactivity of serum samples from individuals, mainly from African countries, who have potentially been exposed to $P$. falciparum, compared to native parasite antigens and subsequent identification of major immunogenic proteins.

\section{Methods}

\section{Study population}

Sera recruited for this study of patients with imported malaria, as well as negative sera (healthy Portuguese individuals who have never been in malaria-endemic countries) were obtained at the Clinical Unit for Tropical Diseases (IHMT, Portugal).

The population for this study consisted of 227 individuals with imported malaria and 23 healthy individuals (residents in Portugal). Most are adults who were in different endemic regions of Africa, including Angola, Guinea, Mozambique, Sao Tome, Cape Verde, Madagascar, Gabon, Congo, Tanzania and Morocco. Some sera were from individuals who had been in Brazil, Ecuador, India, Indonesia, Thailand and Haiti. As a negative control, a group of 23 sera from healthy Portuguese individuals, who had never been in endemic countries, was used.

\section{Consent}

The institutional Ethics Committee at the Instituto de Higiene e Medicina Tropical, Lisbon, Portugal, approved this study protocol. Written informed consent was obtained from the patient for serological assays for malaria and publication for this manuscript (Additional files 1 and 2).

\section{Cultured parasites}

3D7 P. falciparum clones were cultured at 5\% haematocrit, $37^{\circ} \mathrm{C}$ and atmosphere with $5 \%$ of $\mathrm{CO}_{2}$ as described 
by $[15,16]$. Human serum was replaced with $0.5 \%$ AlbuMAXII (Invitrogen ${ }^{\mathrm{Tm}}$ ) in the culture medium. When parasitaemia reached about $8-10 \%$, cultures were harvested for parasite protein extraction.

For the extraction of total proteins of P. falciparum cultures were centrifuged at $5,000 \mathrm{rpm}$ for five minutes at room temperature, and the supernatant was discarded. Pellet was washed with PBS once, resuspended in equal volume of $\mathrm{PBS}$ and a solution of saponin $0.5 \%$ in $\mathrm{PBS}$ and incubated for 10 minutes at $4^{\circ} \mathrm{C}$. Subsequently the mixture was centrifuged at $10,000 \mathrm{rpm}$ at $4^{\circ} \mathrm{C}$ for 10 minutes, the supernatant discarded and parasites washed three times with ice-cold PBS. For the extraction of all proteins of the parasite lysis buffer was added (0.5\% NP-40, $120 \mathrm{mM} \mathrm{NaCl}$, $50 \mathrm{mM}$ Tris- $\mathrm{HCl} \mathrm{pH} \mathrm{7.8),} \mathrm{homogenized} \mathrm{thoroughly} \mathrm{in} \mathrm{the}$ vortex and centrifuged for 15 minutes at $10,000 \mathrm{rpm}$ at $5^{\circ} \mathrm{C}$. The supernatant was recovered, discarding the haemozoin. Proteins were quantified by the Bradford method.

\section{Determination of anti-Plasmodium falciparum antibodies}

It was used the total protein of $P$. falciparum antigen for the search of IgG antibodies in serum from patients with imported malaria. Briefly, 96-well microplates (BD FALCON $^{\mathrm{TM}}$ - EUA) were coated with $100 \mathrm{ng} /$ well of the antigen diluted in bicarbonate buffer $(0.1 \mathrm{M}, \mathrm{pH} 8.5)$, overnight at $4^{\circ} \mathrm{C}$. All ELISAs were carried out using a $100 \mu \mathrm{L}$ reaction mixture volume. After incubation, the plates were washed three times with $200 \mu \mathrm{L}$ of wash buffer (PBS containing 0.05\% Tween 20) per well and the wells were blocked with $5 \%$ low-fat milk in PBS $(\mathrm{pH} 7.2)$ for one hour at room temperature with orbital stirring. Plates were washed three times with $200 \mu \mathrm{L} /$ well with wash buffer. Then the plates were incubated with $100 \mu \mathrm{L} /$ well of diluted sera, for one hour at room temperature with orbital stirring. After incubation with serum samples, the plate was washed five times with 200 $\mu \mathrm{L}$ of wash buffer. For detection of human anti-P. falciparum antibodies, the plate was incubated with $100 \mu \mathrm{L} /$ well of anti-human horseradish peroxidase (HRP)-conjugated IgG secondary antibody (Sigma-USA) for one hour at room temperature with orbital agitation. Then, five washings were made, each with $200 \mu \mathrm{L} /$ well of wash buffer. To reveal the presence of conjugate the plate was incubated with $100 \mu \mathrm{L} /$ well of substrate solution $(10 \mathrm{~mL}$ citrate buffer pH 5.0 with $10 \mathrm{mg}$ OPD, and $10 \mu \mathrm{L}$ of hydrogen peroxide $30 \% \mathrm{v} / \mathrm{v}$ ), for 30 minutes at room temperature and protected from light. To stop the reaction, it was used 4.0 $\mathrm{N}$ sulphuric acid. The cut-off value was defined as a mean of OD from negative control, plus twice standard deviation (Cut-off $=\mathrm{m}+2 \mathrm{SD})$.

\section{Protein characterization and immunoblotting}

Plasmodium falciparum proteins were separated by SDSPAGE with a $12 \%$ polyacrylamide gel. The determination of the protein's molecular mass was estimated by comparison with a commercial HyperPAGE ${ }^{\circledR}$ (Bioline, UK) molecular weight marker. After SDS-PAGE, the gel was withdrawn from the cassette and the gel was equilibrated in transfer buffer for 20 minutes to remove the excess SDS. The membrane and the filter paper used for transfer were equilibrated in transfer buffer for 10 minutes. The antigenic proteins were transferred to a PVDF membrane, previously activated in methanol for five seconds.

The electroblotting was performed in a semi-dry system (BIO-RAD, USA) at $15 \mathrm{~V}$ for 15 minutes. After transfer of proteins from the gel to the membrane, the membrane was washed twice with $15 \mathrm{~mL}$ of PBS for 10 minutes each. This was followed by blocking of the membrane with $15 \mathrm{~mL}$ blocking solution (3\% BSA w/v in PBS buffer) for one hour at room temperature. To remove the excess $\mathrm{BSA}$, the membrane is washed three times, twice with $20 \mathrm{~mL}$ PBS-0.5\% Tween for 10 minutes each, and once with $15 \mathrm{~mL}$ of PBS for 10 minutes. For immunodetection of antigens on the membrane were used serum samples from patients with higher reactivity observed by ELISA $(n=32)$. As negative controls, it was used sera from patients who had never been in contact with the parasite or in malaria-endemic areas. This was followed by incubating the membrane with $10 \mathrm{~mL}$ of primary antibody (1:1,000 in blocking solution) for one hour at room temperature with orbital agitation. After incubation with primary antibodies the membrane was washed three times, twice with $20 \mathrm{ml}$ of PBS- $0.5 \%$ Tween for 10 minutes each, and once with $15 \mathrm{~mL}$ of PBS for 10 minutes. For detection of the antibodyantigen complex the membrane was incubated with $8 \mathrm{~mL}$ of secondary antibody anti-IgG-HRP (Sigma-USA) diluted 1:6,000 in blocking solution for one hour at room temperature with orbital agitation. After the incubation period, the membrane was washed five times with $20 \mathrm{~mL}$ PBS-0.5\% Tween for 10 minutes each. To reveal the presence of the conjugate the membrane is incubated with $15 \mathrm{~mL}$ of developing solution $(7.5 \mathrm{mg}$ diaminobenzidine in PBS with $0.02 \% \mathrm{H}_{2} \mathrm{O}_{2}$ ) at room temperature until colour development. The reaction was quenched with $20 \mathrm{~mL}$ of distilled water. After stopping the reaction membrane was dried and stored for later use in the identification of immunogenic proteins by mass spectroscopy.

\section{Protein identification by mass spectrometry}

Protein bands were excised manually from the SDS-PAGE gel distained with $25 \mathrm{mM}$ ammonium bicarbonate/50\% acetonitrile and dried under vacuum (SpeedVac ${ }^{\circledR}$, Thermo Savant, USA).

The dried gel pieces were rehydrated with $25 \mu \mathrm{L}$ of $10 \mu \mathrm{g} / \mathrm{mL}$ trypsin (Promega, USA) in $50 \mathrm{mM}$ ammonium bicarbonate and digested overnight at $37^{\circ} \mathrm{C}$. 
Tryptic peptides were extracted from the gel with $10 \%$ formic acid $/ 50 \%$ acetonitrile and dried in a vacuum concentrator, resuspended in $10 \mu \mathrm{L}$ of a $50 \%$ acetonitrile/ $0.1 \%$ formic acid solution and mixed (1:1) with a matrix consisting of $a$-cyano-4-hydroxycinnamic acid. Aliquots of samples were spotted onto the MALDI sample target plate. Mass analysis of peptides of each sample was performed with a 4800 MALDI-TOF/TOF Analyzer (ABSciex) in automatic mode with the following settings: for the MS data, m/z range 800 to 4,500 with an accelerating voltage of $20 \mathrm{kV}$ and delayed extraction, peak density of maximum 50 peaks per $200 \mathrm{Da}$, minimal S/N ratio of 10 and maximum peak at 65 . Spectra were internally calibrated with peptides from trypsin autolysis $(\mathrm{M}+\mathrm{H}+=$ 842.509, $\mathrm{M}+\mathrm{H}+=2211.104)$.

For the MS/MS data, fragment selection criteria were a minimum $\mathrm{S} / \mathrm{N}$ ratio of 6 , a maximum number of peaks set at 65 and peak density of maximum 50 peaks per $200 \mathrm{Da}$. For each precursor selected for MS/MS analysis, fragment mass values in the range from $60 \mathrm{Da}$ to $10 \mathrm{Da}$ below precursor mass were used to peptide identification. Protein identification was assigned by peptide mass fingerprinting and confirmed by MS/MS analysis. Mascot (v2.1, Matrixscience) was used for protein identification running on GPS software (Applied Biosystems). Searches were performed against the NCBi (October2011) under all taxonomic categories and the following parameters: (i) two missed cleavages by trypsin; (ii) mass tolerance of precursor ions $25 \mathrm{ppm}$ and product ions $0.3 \mathrm{Da}$; (iii) carboxymethylated cysteines; and, (iv) oxidation of methionine as variable modification. Protein identifications were considered as reliable when the individual ion score for each peptide had a minimum individual score of $95 \%$ and a minimum sequence tag of four amino acids (five consecutive peaks in the MS/MS spectrum).

\section{Results}

In this study, an anti-P. falciparum immunoassay (ELISA) was validated and optimized to distinguish the more reactive sera with regard to the presence of specific anti-P. falciparum IgG antibodies in human serum samples. All sera of patients with imported malaria were analysed for antibodies of the IgG type, at a dilution of $1: 40,000$. These patients were actively recruited in the Clinical Unit for Tropical Diseases (IHMT, Portugal).

To differentiate positive from negative sera a limit point (cut-off) was defined. To determine the cut-off value it was used the 23 sera from healthy Portuguese individuals (control group) who had never been in malaria-endemic areas. The cut-off value was defined as a mean of OD from negative control, plus two standard deviation (cut-off $=m+2 S D$ ); at a dilution of 1:40,000. The weight that the standard deviation (SD) may have on the cut-off value depends on the sensitivity and specificity of this cut-off value will give the method [17]. This was chosen weighting (2SD) because with this cutoff value all negative sera have an absorbance value less than or equal to the cut-off value chosen for dilution.

For the analysis of the results, it was used as discernible criteria the ratio between the absorbance/cut-off; all sera with this ratio above 1.1 were considered positive for anti- $P$. falciparum antibodies (Figure 1). Apart from these groups, another group was set up, the indeterminate group, which were all sera with a value of absorbance within a range of cut-off $\pm 10 \%$ of cut-off value. The results of anti-P. falciparum antibodies research by ELISA indicates 78 positive, 137 negative and 12 indeterminate sera.

Through fractionation of antigens of $P$. falciparum identified by SDS-PAGE associated with the immunoblotting technique, it was identified specific components of parasite that may be associated with acute infection, since the tested sera were from patients with imported acute malaria.

Analysis of immunoblotting profiles of the 32 most reactive sera by ELISA demonstrated a consistent pattern with respect to immunoreactivity of antigens with molecular weights in the range of 40 to $60 \mathrm{kDa}$ (Figure 2). Between 40 and $60 \mathrm{kDa}$, was identified four main bands in the membranes that were analysed by mass spectrometry (Figure 3 and Additional file 3) and it was identified six immunogenic proteins: elongation factor-1 alpha (EF-1 $\alpha)$, protein disulphide isomerase (PDI); phosphoglycerate kinase (PGK); 78 kDa glucose-regulated protein homologue (GRP-78); rhoptry-associated protein 2 (RAP 2) and rhoptry-associated protein 3 (RAP 3) (Additional file 3).

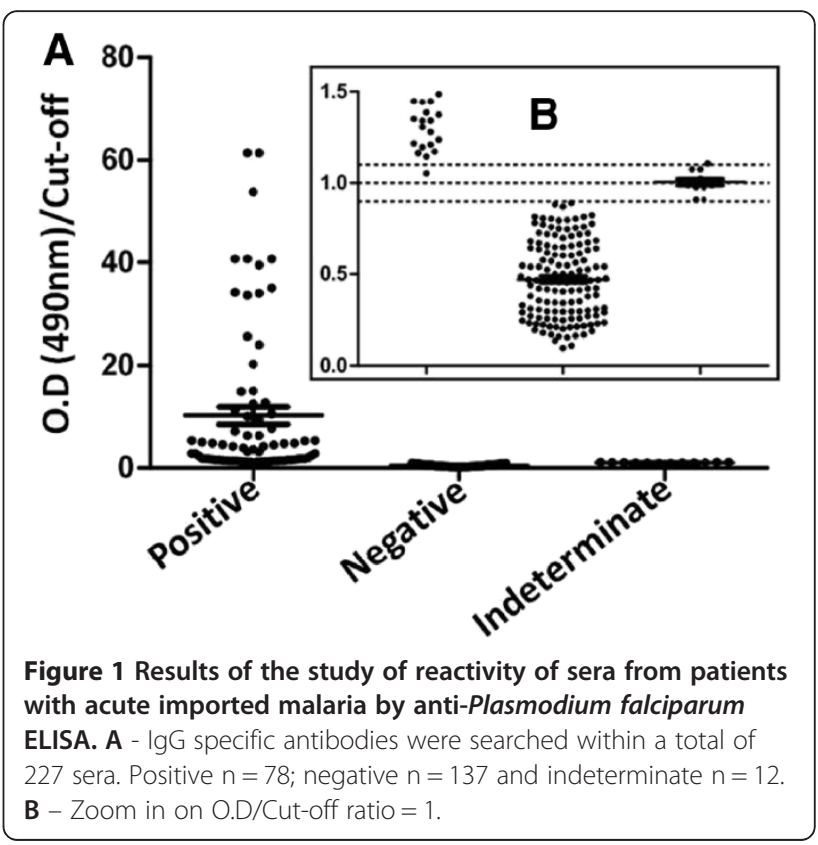




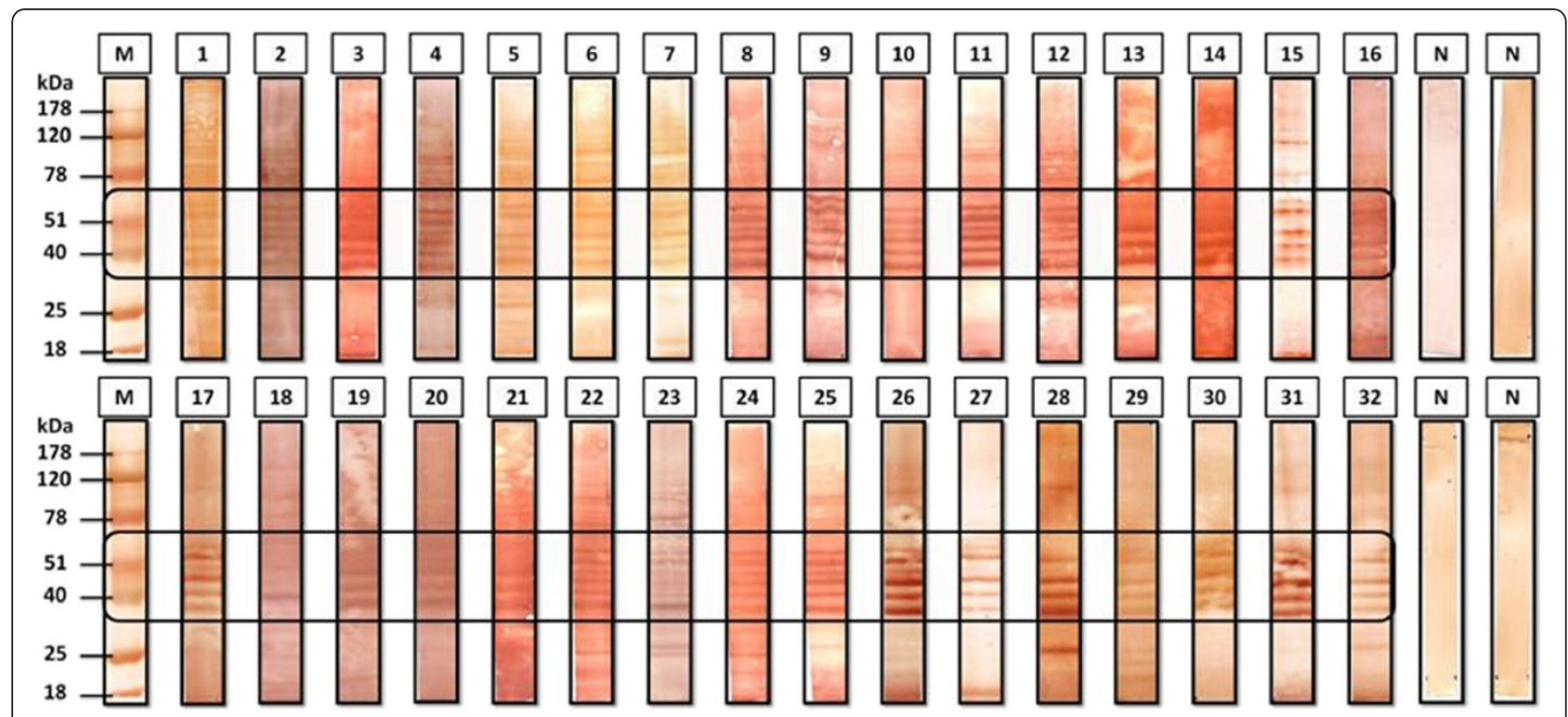

Figure 2 Immunoblotting profiles of the reactive sera by anti-Plasmodium falciparum ELISA. Each strip contains approximately $14 \mu \mathrm{g}$ of P. falciparum. M - Molecular mass marker Hyper PAGE ${ }^{\circledR}, \mathrm{N}$ - negative control sera.

\section{Discussion}

In order to achieve the proposed objectives, it was initially cultivated the parasite P. falciparum (3D7) in an in vitro system of red blood cells (RBCs), followed by the extraction of total native proteins from the parasite

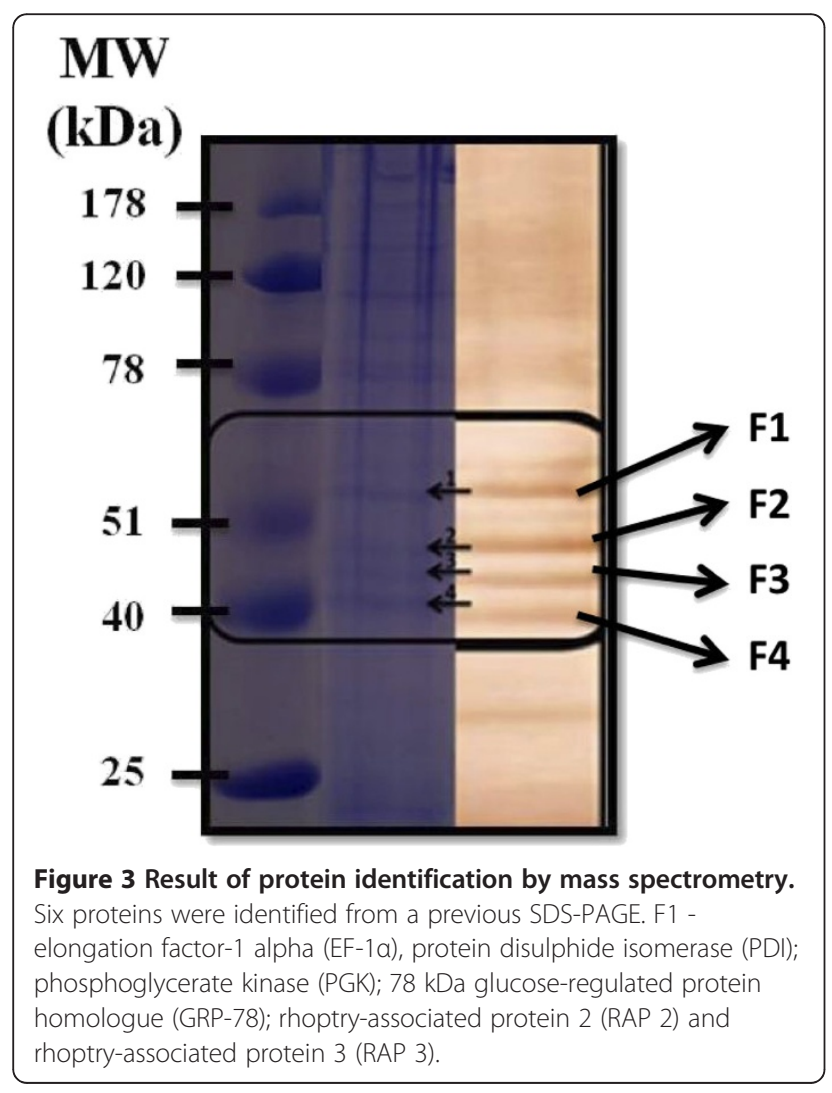

and its quantification by the Bradford method. It was also used enzyme immunoassays (ELISA) to distinguish a serologically negative from a positive population, compared to a control group of healthy individuals $(n=23)$ from Portugal, who had never been in areas that are endemic to malaria. Sera displaying greater reactivity to anti-P. falciparum antibodies by ELISA were analysed by immunoblotting. The analysis of the blots profiles demonstrated a consistent pattern with respect to the immunoreactivity of antigens with molecular weights ranging from 40 to $60 \mathrm{kDa}$ (Figure 2).

The life cycle of $P$. falciparum is complex since its nature requires expression of multiple specialized proteins necessary for the invasion of different types of cells as well as to survive in both invertebrate (mosquito) and vertebrate (human) host organisms [18]. Due to the complexity of the life cycle, each life stage expresses a number of antigenic proteins that can induce an immune response and which presents a real challenge for vaccine design [19].

It was observed that the immunoreactivity of the sera from patients potentially exposed to $P$. falciparum corresponds to some of the antigens prevalent in total protein extracts from parasites and six immunogenic proteins were identified by mass spectrometry (Figure 3 and Additional file 3): elongation factor- 1 alpha (EF-1 $\alpha$ ); protein disulphide isomerase (PDI); phosphoglycerate kinase (PGK); $78 \mathrm{kDa}$ glucose-regulated protein homologue (GRP-78), rhoptry-associated protein 2 (RAP-2) and rhoptry-associated protein 3 (RAP-3).

Eukaryotic elongation factor 1A (eEF1A) plays a central role in protein synthesis, cell growth and morphology $[20,21]$. Malaria parasite possesses two identical genes 
encoding eEF1A (eef1aa and eef1ab). Studies using pbeef1a P. berghei mutants that lack an eEF1a gene show that the level of eEF1A production affects the proliferation of blood stages and parasite fitness [21]. Further attenuation of parasites through elongation of the cell cycle by affecting protein synthesis machinery, might be used for testing the feasibility of the creation of attenuated live parasites as vaccine [21].

Proteins disulfide isomerases (PDI) are a family of redox chaperones that are implicated in protein unfolding and trafficking across the endoplasmic reticulum (ER) and towards the cytosol, a thiol-based redox locus for antigen processing [22].

The major pathway for glucose metabolism in $P$. falciparum-infected RBCs is anaerobic glycolysis. PGK is one of the key enzymes of this pathway as it generates ATP [23]. The GRP-78 is a heat shock-related protein and may play a role in the adaptation of parasites during their complex life cycle [24]. The stages of the parasite that grow and multiply in RBCs cause all the pathological effects and accordingly the invasion of RBCs is one of the most important steps in the parasite life cycle.

The rhoptries are specialized secretory organelles located at the apical end of merozoites, the form of the parasite that invades RBCs. Its contents include proteins that have been implicated as having a role in the invasion process such as RAP-2 and RAP-3 [25,26]. RAP-1 controls RAP-2 or RAP-3 transport toward the rhoptries during invasion, when the gene encoding RAP-1 is interrupted, the traffic of either of the other two proteins is affected and such proteins remain trapped in the endoplasmatic reticule. Invasion does not become inhibited when the gene encoding RAP-3 is interrupted but does become reduced to some degree. These observations suggest that the loss of RAP-3 is compensated for by the presence of RAP-2 and vice-versa. Several studies have demonstrated the importance of responses mediated by antibodies to rhoptry proteins in protection against malaria. In vitro studies showed that monoclonal antibodies directed against RAP-2 provide substantial inhibition of merozoites in invasion of RBCs [27]. Experimental evidence demonstrated that RAP-2 is a ligand used by merozoites to invade RBCs. This protein has four RBC binding sequences defined by high-activity binding peptides (HABPs) $26220\left({ }^{61}\right.$ NHFSSADELIKYLEKTNINT $\left.{ }^{80}\right)$ and $26225\left({ }^{161}{ }^{1 K K N P F L R V L N K A S T T T H A T ~}{ }^{180}\right)$ in the protein's amino terminal and central parts and HABPs $26229\left({ }^{241}\right.$ RSVNNVISKNKTLGLRKRSS $\left.{ }^{260}\right)$ and 26235 $\left({ }^{361}\right.$ FLAEDFVELFDVTMDCYSRQ $\left.{ }^{380}\right)$ in the carboxyl terminal region [25]. All HABPs bind to a $62-\mathrm{kDa}$ protein located on the RBCs surface. HABPs 26225 and 26229 also bind to the $42-\mathrm{kDa} \mathrm{RBC}$ proteins.

Additionally, RAP-3 can act as an auxiliary protein in the RAP complex in maintaining the cycle during blood stage. Invasion does not become inhibited when the gene encoding RAP-3 is interrupted but does become reduced to a certain extent. RAP-3 shows two HABPs: $33860\left({ }^{61}\right.$ FNHFSNVDEAIEYLKGLNIN $\left.{ }^{80}\right)$ and 33873 $\left({ }^{321}\right.$ KNRTYALPKVKGFRFLKQLF $\left.{ }^{340}\right)$ [25].

Rhoptry-associated proteins may be used as targets for multi-antigen, multistage, subunit-based, anti-malarial vaccine development. A completely effective vaccine has not yet been developed against this disease, mainly due to the incomplete knowledge of the intimate molecular interactions between parasite proteins and their specific host cell membrane receptor(s) during invasion. The proteins identified in this study may be the starting point for more detailed studies regarding control strategies and disease prevention.

\section{Conclusions}

In this study, analysis of immunoblotting profiles of serological reactive sera from malaria patients demonstrated a consistent pattern with respect to immunoreactivity of antigens with molecular weights in the range of 40 to $60 \mathrm{kDa}$. Between 40 and $60 \mathrm{kDa}$, it was identified four main bands in the membranes that were analysed by mass spectrometry and it was identified six immunogenic proteins: elongation factor- 1 alpha $(E F-1 \alpha)$, protein disulphide isomerase (PDI); phosphoglycerate kinase (PGK); $78 \mathrm{kDa}$ glucose-regulated protein homologue (GRP-78); rhoptry-associated protein 2 (RAP 2) and rhoptry-associated protein 3 (RAP 3).

\section{Additional files}

Additional file 1: Approval of the Ethics Committee of the Institute of Hygiene and Tropical Medicina, Lisbon - Portugal (in Portuguese). Additional file 2: Informed consent model used in this study (in Portuguese).

Additional file 3: Proteins of Plasmodium falciparum identified by mass spectrometry.

\section{Competing interests}

The authors declare that they have no competing interests.

\section{Authors' contributions}

RMC, FN, KPS, RV, MSS conceived and designed the experiments; RMC, FN, RV, MSS analysed the data; RMC, KPS, MSS wrote the paper; all authors have read and approved the final manuscript.

\section{Acknowledgements}

We would like to thank all the subjects who agreed to adhere to the study and the laboratorial support from Paula Maduro and Laura Cravo.

\section{Author details}

${ }^{1}$ Centre for Malaria and Tropical Diseases, Instituto de Higiene e Medicina Tropical, Universidade Nova de Lisboa, Rua da Junqueira, 100, Lisbon 1349-008, Portugal. 'QOPNA, Department of Chemistry, University of Aveiro, Aveiro, Portugal.

Received: 14 January 2013 Accepted: 9 March 2013

Published: 18 March 2013 


\section{References}

1. Tuteja R: Malaria - an overview. FEBS J 2007, 274:4670-4679.

2. WHO: World Malaria Report 2011. Geneva: World Health Organization/Global Malaria Programme; 2011.

3. WHO: World Malaria Report 2010. Geneva: World Health Organization/Global Malaria Programme; 2010.

4. Kain KC, Keystone JS: Malaria in travellers. Epidemiology, disease and prevention. Infect Dis Clin North Am 1998, 12:267-284.

5. WHO: International travel and health, 2011 - situation as on 1 January 2011. Malaria. Geneva: World Health Organization; 2011.

6. Estatísticas de Saúde - Doenças de Declaração Obrigatória, 2004-2008. Available on line at: [http://www. dgs.pt] Accessed February 16, 2011 (in Portuguese).

7. Jennings RM, DE Souza JB, Todd JE, Armstrong M, Flanagan KL, Riley EM, Dohert JF: Imported Plasmodium falciparum malaria: are patients originating from disease-endemic areas less likely to develop severe disease? A prospective, observational study. AmJTrop Med Hyg 2006, 75:1195-1199.

8. Marsh K, Kinyanjui S: Immune effector mechanisms in malaria. Parasit Immunol 2006, 28:51-60

9. Cohen S, McGregor IA, Carrington S: Gamma-globulin and acquired immunity to human malaria. Nature 1961, 192:733-737.

10. McGregor IA, Carrington SP, Cohen S: Treatment of East African $P$. falciparum malaria with West African human $\gamma$-globulin. Trans $R$ Soc Trop Med Hyg 1963, 57:170-175.

11. Sabchareon A, Burnouf T, Ouattara D, Attanath P, Bouharoun-Tayoun H, Chantavanich P, Foucault C, Chongsuphajaisiddhi T, Druilhe P: Parasitologic and clinical human response to immunoglobulin administration in falciparum malaria. AmJTrop Med Hyg 1991, 45:297-308.

12. Gysin J, Moisson P, Pereira da Silva L, Druilhe P: Antibodies from immune African donors with a protective effect in Plasmodium falciparum human infection are also able to control asexual blood forms of the parasite in Saimiri monkeys. Res Immunol 1996, 147:397-401.

13. Genton B, Betula I, Felger I, Al-Yaman F, Anders RF, Saul A, Rare L, Baisor M, Lorry K, Brown GV, Pye D, Irving DO, Smith TA, Beck H, Alpers MP: A Recombinant blood-stage malaria vaccine reduces Plasmodium falciparum density and exerts selective pressure on parasite populations in a phase 1-2b trial in Papua New Guinea. J Infect Dis 2002, 185:820-827.

14. Richards JS, Beeson JG: The future for blood-stage vaccines against malaria. Immun Cell Biol 2009, 87:377-390.

15. Trager $W$, Jensen JB: Human malaria parasites in continuous culture. Science 1976, 193:673-675.

16. Thaithong S, Seugorn A, Beale GH: Culturing Plasmodium falciparum from finger-prick samples of infected blood. Trans Royal Soc Trop Med Hyg 1994, 88:490.

17. Hackett DJ, Zhang C, Stefanescu C, Pass RF: Enzyme-Linked Immunosorbent Assay for measurement of cytomegalovirus glycoprotein B antidoby in serum. Clin Vac Immunol 2010, 17:836-839.

18. Florens L, Washburn MP, Raine JD, Anthony RM, Grainger M, Haynes JD, Moch JK, Muster N, Sacci JB, Tabb DL, Witney AA, Wolters D, Wu Y, Gardner MJ, Holder AA, Sinden RE, Yates JR, Carucci DJ: A proteomic view of the Plasmodium falciparum life cycle. Nature 2002, 419:520-526.

19. Vaughan K, Blythe M, Greenbaum J, Zhang Q, Peters B, Doolan DL, Sette A Meta-analysis of immune epitope data for all Plasmodia: overview and applications for malarial immunobiology and vaccine-related issues. Paras Immunol 2009, 31:78-97.

20. Vinkenoog RR, Sperança MA, van Breemen O, Ramesar J, Williamson DH, Ross-MacDonald PB, Thomas AW, Janse CJ, del Portillo HA, Waters AP: Malaria parasites contain two identical copies of an elongation factor 1 alpha gene. Mol Biochem Parasitol 1998, 94:1-12.

21. Janse CJ, Haghparast A, Sperança MA, Ramesar J, Kroeze H, del Portillo HA, Waters AP: Malaria parasites lacking eef1a have a normal S/M phase yet grow more slowly due to a longer G1 phase. Mol Microbiol 2003, 50:1539-1551.

22. Stolf BS, Smyrnias I, Lopes LR, Vendramin A, Goto H, Laurindo FRM, Shah AM, Santos CXC: Protein disulfide isomerase and host-pathogen interaction. Sci World J 2011, 11:1749-1761.

23. Smith CD, Chattopadhyay D, Pal B: Crystal structure of Plasmodium falciparum phosphoglycerate kinase: evidence for anion binding in the basic patch. Biochem Biophys Res Comm 2011, 412:203-206.
24. Kumar N, Syin CA, Carter R, Quakyi I, Miller LH: Plasmodium falciparum gene encoding a protein similar to the $78-\mathrm{kDa}$ rat glucose-regulated stress protein. PNAS 1988, 85:6277-6281.

25. Rodriguez LE, Curtidor H, Urquiza M, Cifuentes G, Reyes C, Patarroyo ME: Intimate molecular interactions of Plasmodium falciparum merozoite proteins involved in invasion of red blood cells and their implications for vaccine design. Chem Rev 2008, 108:3656-3705.

26. García J, Curtidor H, Vanegas M, Arévalo-Pinzon G, Patarroyo MA, Patarroyo ME: Conserved regions of the Plasmodium falciparum rhoptry-associated protein 3 mediate specific host-pathogen interactions during invasion of red blood cells. Peptides 2010, 31:2165-2172.

27. Schofield L, Bushell GR, Cooper JA, Saul AJ, Upcroft JA, Kidson C: A rhoptry antigen of Plasmodium falciparum contains conserved and variable epitopes recognized by inhibitory monoclonal antibodies. Mol Biochem Parasitol 1986, 18:183-195.

doi:10.1186/1475-2875-12-100

Cite this article as: Costa et al:: Immunoproteomic analysis of Plasmodium falciparum antigens using sera from patients with clinical history of imported malaria. Malaria Journal 2013 12:100.

\section{Submit your next manuscript to BioMed Central and take full advantage of:}

- Convenient online submission

- Thorough peer review

- No space constraints or color figure charges

- Immediate publication on acceptance

- Inclusion in PubMed, CAS, Scopus and Google Scholar

- Research which is freely available for redistribution 